\title{
The Role of Cheongsam Culture in Interpretation of the Inner Activities of Movie Characters
}

\author{
Shuxian Huang \\ The Fashion Design and Management branch \\ Jiangxi Institute of Fashion Technology \\ Nanchang, China \\ E-mail: 362112768@qq.com
}

Keywords: Cheongsam; Inner Feeling of Character; Role; in the Mood for Love; the Flowers of War; Lust Caution

\begin{abstract}
This Cheongsam is a traditional clothing of China and is also known as national apparel, which meets the requirements of Chinese traditional aesthetics with deep national cultural heritage and unique status and charm. Cheongsam is widely used in movies, which shows the changes of the identity and status of female subjects and awakening of female self-cognition, and it has become a cultural symbol for national characteristics. Set in In the Mood for Love, The Flowers of War and Lust Caution, this paper deepens the understanding of cheongsam culture, and analyzes the practical application of cheongsam in movies, especially the important role of analyzing the inner feelings and characters of figures.
\end{abstract}

\section{Introduction}

Cheongsam is the most typical clothing of females in China and is also known as national apparel, which meets the requirements of Chinese traditional aesthetics with deep national cultural heritage and unique status and charm and is deeply loved by Chinese and foreign people.

From Qing Dynasty to 1970s, cheongsam is always the mainstream dress in China. Modern cheongsam comes from the gown of banner people. Qing Dynasty is a period which has luxurious decoration. The crafts with high difficulty like "rolling, decorating, inserting and hanging" are used in "18 rolling" cheongsam with 18 ornamental welts, which makes the decoration of cheongsam more perfect. It is also widely used in movies, which not only shows the changes of female identity and status, but also expresses the awareness of self-cognition, and becomes a cultural symbol of national characters. This paper set in three movies, In the Mood for Love, the Flowers of War and Lust and Caution, which deepens the understanding of cheongsam culture, and analyzes the concrete application of cheongsam culture in movie and especially the important role in inner feelings and characters.

\section{The Humanistic Connotation of Cheongsam}

The Earliest image of cheongsam is "loose and flat, covering the ankles, a frock covering from neck to feet and also the formal beauty of women." Take the leg opening of cheongsam as an example, western clothing have front and back leg opening to make people walk with space. But cheongsam has leg opening on sides, which make women walk freely and also show the female shape perfectly. The gourd shaped line of chest, hip and waist can be presented in a wonderful way, not only sexy but also gentle and poetic. Thus, western clothing historian named leg opening of "appealing glance", which is also the contribution of China to clothing history of the world. With the development of society, styles and modelings of modern cheongsam have changed a lot. No matter how, the essential characters like gourd shaped line of China collar, plate button and chest, waist and hips will not be changed. It is worth mentioning that in recent years, the earliest traditional design of cheongsam in films and television programs has been changed. Different designs of cheongsam have become the 
medium of culture transmission, and the symbols of identity and social status and also the medium of inner feelings of characters and personality. In the movie like In the Mood for Love, Dangerous Liaisons, the Flowers of War and Sound of the Wind, cheongsam has become a cultural scenery line. Professor Li Lixin said, "Film art is an important medium of cultural transmission, which contains a lot of art elements. In the movie language system, clothing is not only representative elements of aesthetic perception, but also contains various information for people who wear it." In the film creation, there are colorful languages. Besides, the clothing has its own charm in film development, which builds special character images and it is also a reflection of historical background.

From the perspective of cultural study, cheongsams in movie are not only the symbol of different vocation, identity and age, but also the traditional Chinese aesthetic standard. Sun Yufeng said, "Cheongsam is a typical symbol of Chinese cultural accumulation, which shows the harmonious beauty of theory that man is an integral part of nature. Women with cheongsams show the dispositions of virtuous, elegant, gentle and beautiful, which are an incorporation of inner and external beauty and the essence of Chinese culture." Tradition aesthetics think highly of poetic imagery beauty and contain feudal ethics and the meaning of "home". In Raise the Red Lantern, Songlian wears a closefitting cheongsam and changes from a student to a concubine. The inner meaning is that Songlian submits to feudal ethical code; 23 cheongsams of Miss. Su in movie named In the Mood for Love not only brings

visual feast of female pretty figure to audience, but also reflects the internal struggle of Miss. Su. The detail change of cheongsam in this movie makes the audience directly find out the mental changes of characters, emotional disputes with Zhou Muyun, but they dare not to transgress the bounds.

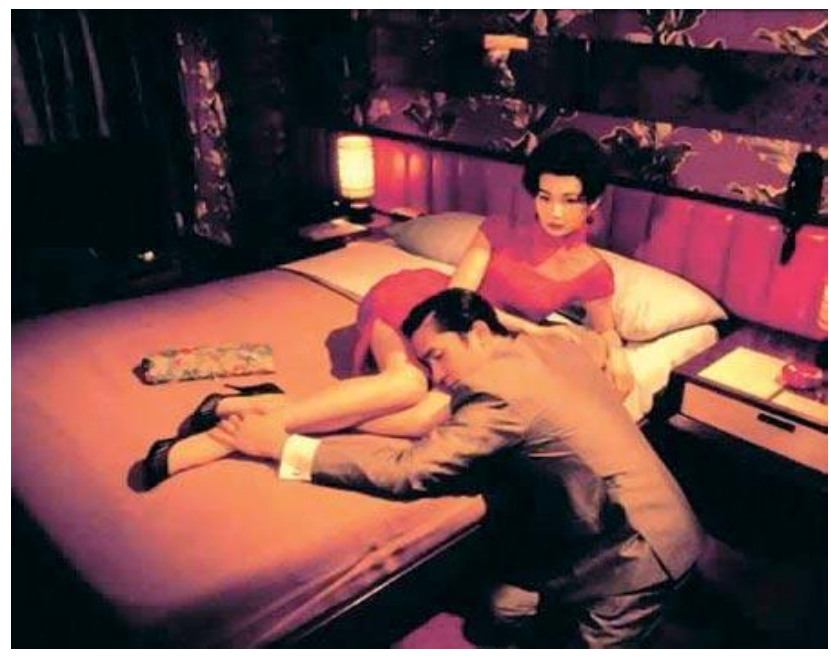

Figure 1. The 23rd Cheongsam of Maggie Cheung in the movie In the Mood for Love

All the fans who have seen the movie In the Mood for Love also know that, Maggie Cheung has dressed 23 different cheongsams in the movie. It seems that the audiences like enjoying a grand visual feast. An elegant woman is surrounded by 23 blossomy cheongsams in the whole process, which makes her elegant, gloomy, graceful, sorrowful and generous. Each cheongsam shows the mood of heroine of this moment. Although Maggie has changed cheongsams, but her mature and gentle never leave, which adds a highlight to the movie.

With the continuous infiltration of western culture, the styles and forms of Chinese culture have changed. The design of cheongsam fits women better with visual beauty. Leg opening can fit legs much closer and the side slits much higher. The materials and colors of cheongsam are enriched; lace and silk fabrics begin to be used in cheongsam. Wu Gang once said, "From the perspective of art aesthetics, visual art and aesthetic psychology have a close relation, which includes two core propositions, that is 'look' and 'desire"". To become "the subject of desire"shows that the awakening of female self-consciousness. They choose to use cheongsam to draw people's attentions and to satisfy their inner demands. For example, Wang Yazhi in Lust and Caution, in order to approach Mr. 
Yi, she wears cheongsam made of lace and silk to show her charms and also to show her identity from a female special agent to a concubine.

It is calculated that Rebecca Tang has changed 27 different cheongsams in Lust and Caution, which breaks the record of Maggie Cheung changes 23 cheongsams in the movie named In the Mood for Love. Someone once said that cheongsams in movie named In Mood for Love by Wang Jiawei fit his dispirited and romantic movie style. Li An does not specially stress atmosphere in Lust and Caution, he just indicates the environment transition through the style and material of cheongsams.

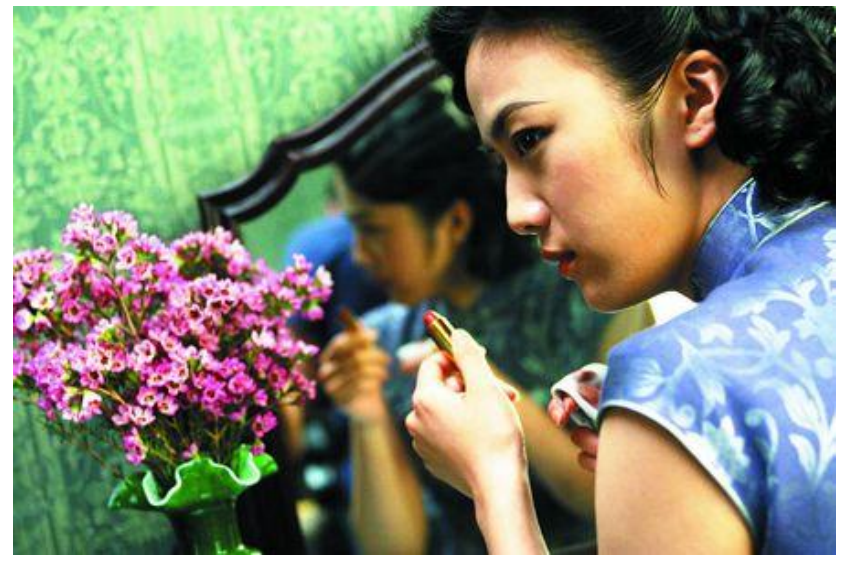

Figure 2. The Cheongsam of Rebecca Tang in Lust and Caution

After several months of "lady class" training, Wang Yazhi acted by Rebecca Tang surprises everyone. She is tall and has a neat figure, and is a little classical sexy with cheongsam. A fan says that Rebecca Tang with cheongsam in Lust and Caution is better, "combining the life and movie together, and cheongsam does not steal her thunder with the help of manipulation."Science fiction movie director from Hollywood once said to media that he was impressed by the clothing in the movie In the Mood for Love. Lust and Caution stresses humanity, and clothing of Rebecca Tang in the movie is suitable for her role. There is one scene that in a Japanese tavern, Wang Yazhi closefitting cheongsam. Her gestures and expressions perfectly demonstrate female outline, and also indicate her feelings to Mr. Yi. This transition is also an important transition, which enriches her characters and serves as an artful bedding that she saves Mr. Yi and violates her tasks.

Movie the Flowers of War by Yimou Zhang mainly uses cheongsam as clothing. On one hand, it represents the images of enchanting prostitutes with heavy makeup. On the other hand, it subverts the traditional prostitute image. When the country is defeated and the home is lost, these prostitutes throw themselves into the breach to save innocent children. This internal and external contrast has a powerful visual impact. The images of prostitutes with cheongsams and their honorable and unyielding images of saving the nation are combined perfectly. In this paper, we are going to analyze their complicated inner feelings in the movie.

\section{A Case Study of Cheongsams in the Flowers of War for Interpreting Inner Activities of Characters}

Cheongsam as feature clothing in the Flowers of War by Zhou Yimou, represents the beauty of cheongsam and humanistic connotation in a perfect way, which not only shows the visual art of appealing female pretty figure, but also reflects the noble beauty of human nature of Chinese women with the help of cheongsams. The movie is a narration of a moving story when Japanese soldiers invaded Nanjing, and prostitutes saved students. The first time they come on the stage is that they wear colorful cheongsams and seek asylum in a church. Through a slow motion, students see some enchanting women enter the church from beautiful paper-cutting pasted on panes. This contrast technique deepens the secular idea that students are innocent while prostitutes are lowly and filthy. The close-fitting cheongsam features the breast line and waist line, and fat butt. The bright colors of cheongsam can be compared with beautiful paper-cutting in the church. Large area of flower and 
geometric pattern montage in cheongsam represents blossomy vitality of these women. Cheongsams with high leg opening shows the beauty of female sexy legs faintly with visual attraction; and the openwork stockings and bags also build the fascinating images and indicate their status. When they ran for their life, they cannot forget to keep beautiful, and it shows that they used to keep their beautiful appearances.

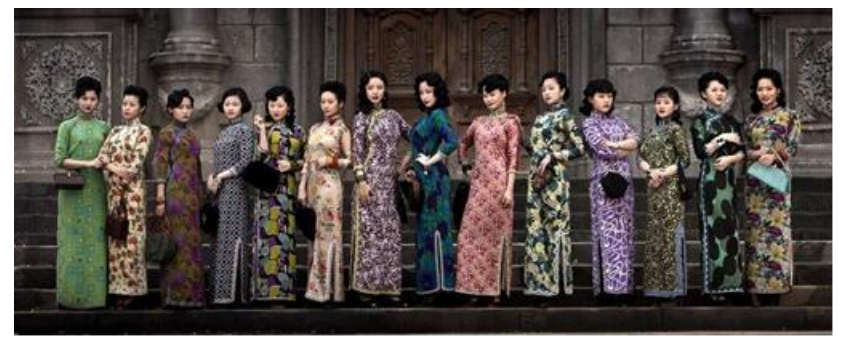

Figure 3. Gorgeous Cheongsams in the Flowers of War

The next scene is that shabby women show up in front of students and John. Especially the flirt between Yumo and John, director uses slow motion to shoot red flowery cheongsam of Yumo. Wellshaped image and waist fully show her hot shape. This scene shows up in the movie more than once, which makes John and audience understand that she is seducing this man. From the composition of the movie, it shows that sexual passion between a man and a woman, and also express bravery, calm, confidence and intelligence of Yumo, and she also wants John to take them away from this city. When Japanese soldiers robbed students in the church, Shujuan did not expose prostitutes who hid in cellar. Yumo is grateful, and her red cheongsam shows her true thanks and confession and her gentle, strength and self-giving, which serves as the bedding of her sacrifice.

From the perspective of color psychology, green is the most peaceful color, and also the most trustworthy, safe and fair as well as warm color. In movie, Doukou wears a cheongsam with green yellow figures. At first glance, Pusheng looks like her brother. She is willing to look after sick Pusheng. Cheongsam with green yellow figures shows that during chatting with Pusheng, Doukou wants to forget her dangerous situation of war and death, and yearns for a happy, calm, peaceful and simple life.

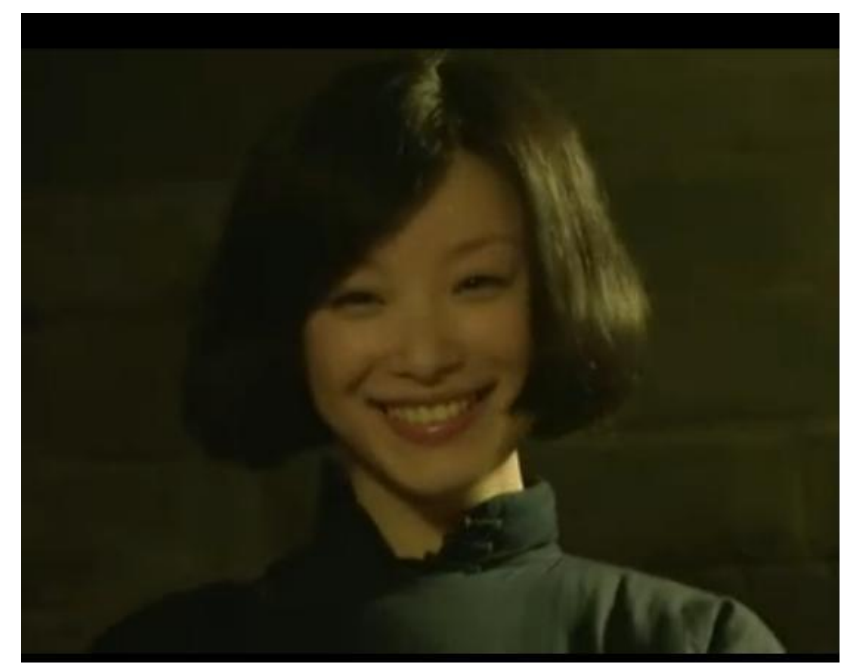

Figure 4. Charming Yumo in the Flowers of War

The most classic scene of this movie is that these twelve prostitutes are ready to sacrifice themselves and face to deaths. Yumo said, we need to do a great thing to erase our bad names. Hongling said, right! They all say we are heartless bitches. Tomorrow we are going to do a meaningful thing. And cheongsams make them more respectful. They are not dirty prostitutes any more, but some noble Chinese women. Director uses slow motions to show that they slowly unlock buttons, and take off colorful cheongsams and wear clue cuttony cheongsams. When John is making 
up, they talk and laugh, which shows that they become young and innocent, and also indicates that they are also some simple and naive girls. They hate to be prostitutes who want to make clients laugh and sneer at each other, but some unsophisticated students who are facing to challenges and taking care of each other. At the same time, the blue color of cheongsam is also a metaphor of their forthcoming miserable fate. But their souls are purified and their wish of gaining recognition and respect from others is also accomplished.

\section{Summary}

At present, the unique charm of movie art leads our life. A successful movie could lead the direction of trend and fashion, and also impress the audience. Now when enjoying the movie, the audiences not only focus on the plot, but also pay attention to the clothing design in movie. For example, in the movie named In the Mood for Love, these 26 gorgeous cheongsams will never be forgotten by people. Clothing in movies could reveal the inner feelings of characters, build the characters, and express the theme of movie. Some excellent movies could always reveal the emotional atmosphere of the movie, express the inner activities of characters and deepen the theme. Those 26 cheongsams dressed by Maggie Cheung in the movie In the Mood for Love are well-tailored with various bright colors. Line of beauty is the best description of elegance and loneliness of a woman. In this movie, cheongsam has become a silent language. With the help of color and style transition, the multi-level emotions of heroine are presented to audience. The proper application of clothing is helpful for audience to have a better understanding of figures' characters and plot.

It is particularly worth mentioning that one of the most representatives is the cheongsam dressing in the Flowers of War, which integrates the essence of Chinese traditional culture, and has typical national characteristics. Cheongsam with bright colors, classical patterns and luxurious fabrics in movie, not only successfully builds unique images of characters, but also brings intuitive visual experience to audience; as for the change of cheongsam style, especially when women take off gorgeous cheongsams and wear a blue cottony cheongsam, which describes their beauty and the transition of their inner activities and reflects the change of their character feelings, and subverts the aesthetic standard of prostitute who wear cheongsams.

\section{References}

[1] Li Lixin. An Analysis of Clothing Culture in Movie. [J]. 2012(13) : 137-138.

[2] Tang Yong. An Analysis of Rise and Decline of Cheongsam from the Perspective of Feminist Consciou sness. [J] Journal of South China Normal University. 2007 （2） : 86.

[3] Sun Yufeng. An Analysis of Cheongsam Application in Movie Characters[J]. Movie Review. 2008 (14) : 19

[4] Wu Gang. Costume Aesthetics [M] Beijing: China Textile Press. 2000:83.

[5] Ding Yinqiao. The Theme and The Artistic Attraction of Clothng Colors in Firms[J]. Film Literature. 2010 (19)

[6] Han Jieyin. An Analysis of Expression Function of "clothing color" in Film and Television Arts.[J]. Film Literature.2012 (15)

[7] Xu Bing. The Research of Clothing Brand Image.[J]. China National Knowledge Infrastructure. 2002 (1): :13-19

[8] Liu Shuzhen. Yang Honglin. An analysis of the Advertisements under the Semiotic Perspective. [J]. Journal of Wuhan Textile University 2009 (6) : 42-43 
[9] Shi Tong. An Analysis of Costume Language Characteristic in Modern Films and Television Program. [J]. Decoration 2011 (6) : 42-43

[10] Xie Nan. The Research of Character Costume Design and Clothing in Films and Television Program. [D]. Changchun University of Technology 2012. 